\title{
VIRGílIO E OS JOGOS FÚNEBRES TROIANO-ROMANOS
}

\author{
ZÉLIA DE ALMEIDA CARDOSO \\ Departamento de Letras Clássicas e Vernáculas \\ Faculdade de Filosofia, Letras e Ciências Humanas \\ Universidade de São Paulo
}

\begin{abstract}
RESUMO
To livro V da Eneida encontramos minuciosa descrição dos jogos fúnebres organi1 zados por Enéias para a celebração do primeiro aniversário da morte de Anquises. Embora inspirado na Ilíada, o texto é bastante original e dá oportunidade a numerosos comentários tanto por aludir a práticas muito difundidas em Roma tais como as homenagens aos mortos, as comemorações dos aniversário da morte de pessoas ilustres, as competições esportivas e as cerimônias de purificação - entre as quais a suouetaurilia -, como por descrever o desfile juvenil denominado ludus troianus.

Palavras-chave: Eneida; Jogos fúnebres; Homenagens aos mortos; Competições esportivas; Ludus troianus.
\end{abstract}

0 livro V da Eneida é consagrado, em sua maior parte, à narração descritiva dos jogos fúnebres organizados por Enéias para a celebração do primeiro aniversário da morte de Anquises, configurando-se como a principal peça poética latina que trata de competições esportivas. 0 texto, como tudo que é da lavra de Virgílio, propõe uma série de questões ao leitor, estimulando-lhe a reflexão e oferecendo campo a numerosos comentários.

0 estudioso dos problemas virgilianos, ao defrontar-se com o livro $V$, tem sua atenção despertada de início para a composição dessa parte da obra, cuja montagem é peculiar se for levado em consideração o conjunto do poema. Perret (Virgile, 1978, p. 149-151), comentando o referido livro nas "notas complementares" apostas à sua tradução da Eneida, lembra a posição da crítica tradicional que desde há muito tem observado a falta de unidade do livro $\mathrm{V}$, no qual a narrativa dos jogos, que ocupa dois terços do texto, forma um bloco bastante coerente mas distinto do último terço, no qual se explora o incêndio dos navios troianos, provocado por mulheres instigadas por Î́ris, a aparição de Anquises ao filho, em sonhos, a fundação da cidade de Acesta, a partida dos guerreiros para a Itália e a morte do piloto Palinuro.

Para Perret, esse último terço poderia parecer um emaranhado de fatos mal ligados, introduzidos sem necessidade no chamado "livro dos jogos", talvez para manter o equilíbrio 
canônico, se não houvesse real importância nesses episódios, diante dos quais a descrição das competições é que assume uma desproporção exagerada. Na sua opinião, a extensão do relato dos jogos é excessiva e só pode ser explicada se se considerar que o número de versos utilizados para tal fim (596 dos 871 que compõem o livro) se aproxima do que foi empregado para a narração da catábase do livro VI (637 versos: do 264 a0 901), o que determinaria a simetria dos dois livros nos quais a figura de Anquises teria um destaque especial.

A descrição dos jogos, no entanto, se nos afigura como um trecho importante do poema e sobre ela faremos algumas reflexões. A Eneida, como se sabe - e Grimal (Grimal, 1985, p. 171) o acentua em Virgile ou la seconde naissance de Rome-, é uma espécie de epopéiasíntese com a qual o poeta, inspirando-se naturalmente nos poemas homéricos, procurou realizar os desígnios de Augusto e criar o verdadeiro poema épico da romanidade. Para exaltar Roma, o povo romano e o Principado, valeu-se de modelos antigos mas utilizou a lenda mítica como uma espécie de pano-de-fundo contra o qual se projetasse o momento presente.

No tratamento da lenda Virgílio manipulou numerosas fontes e elaborou a matéria obtida com originalidade criativa, mas na montagem esquemática do texto recorreu sobretudo à Odisséia e à Iliada. Compôs matemática e arquitetonicamente uma obra híbrida, dividida em doze livros, destinando os seis primeiros ao relato da viagem de Enéias, inspirado na Odisséia, e os seis últimos ao das lutas travadas no Lácio para o estabelecimento dos troianos - a influência vem agora predominantemente da Ilíada.

0 livro $V$ se situa, pois, na primeira metade e faz parte da narrativa da viagem. Nos quatro primeiros livros o poeta relatara a chegada de Enéias e de seus companheiros a Cartago, fizera a súmula da guerra de Tróia e das aventuras vivenciadas posteriormente pelos troianos, cedendo a palavra narradora a Enéias, e descrevera o caso de amor em que se envolveram a soberana cartaginesa e o chefe troiano, desfeito pela súbita partida de Enéias, que retoma a viagem interrompida, e pelo conseqüente suicídio de Dido.

0 livro $\mathrm{V}$-sobre o qual nos deteremos - se inicia com referências à viagem reencetada. Os sete primeiros versos podem ser considerados como versos de transição. Virgílio nos mostra Enéias e seus companheiros já em pleno mar, a caminho da Itália. 0 chefe troiano avista 0 clarão das chamas da pira em que Dido se suicidara e, embora desconheçam a causa do fogo, os troianos se afligem, por saberem, furens quid femina possit ("o que pode fazer uma mulher apaixonada" - V, 6).

Em seguida, o poeta inicia o preâmbulo da narração dos jogos, falando de uma nuvem negra que pairou sobre os navios escurecendo o dia e tumultuando as águas. Está criado 0 motivo que vai obrigar os troianos a interromper a viagem mais uma vez e a aportar na Sicilia. Enéias se vale do imprevisto para realizar cerimônias e jogos fúnebres em homenagem ao pai no primeiro aniversário da morte de Anquises e no próprio local em que o ancião morrera.

0 espanto do piloto Palinuro com a tempestade iminente se extravasa na interpelação a Netuno: 


\section{Heu! quianam tanti cinxerunt aethera nimbi?}

Quidue, pater Neptune, paras? (V, 10-11)

("Ai de nós! Por que nuvens tão grandes cobriram o céu?

0 que nos preparas, pai Netuno?")

Essa interpelação, por curta e usual que seja, merece, a nosso ver, um comentário. Na Eneida, Netuno é freqüentemente apresentado como uma divindade favorável a Enéias e a seus companheiros, uma vez que tem ligações afetivas com Vênus, como ele próprio diz (Aen. V, 799 e ss.), pelo fato de ter a deusa nascido da espuma do mar e de ter sido levada pelas ondas de Citera a Chipre. Essa afeição teria feito com que Netuno protegesse Enéias no momento em que este combatia com Aquiles, em Tróia, envolvendo-o em uma nuvem (Cf. Il. XX e XXI), muito embora estivesse ainda ressentido com o perjúrio de Laomedonte, que não lhe concedera a recompensa devida pelo auxílio na construção das muralhas da cidade, e tivesse vontade de derrubá-las com suas próprias mãos (cuperem cum uertere ab imo/structa meis manibus perjurae moenia Troiae - V, 810-811). Mais tarde, quando Enéias e seus companheiros se encontravam em plena viagem, Netuno mais uma vez os socorrera, amainando a tempestade provocada pelos ventos de Éolo a pedido de Juno (I, 124 e ss.).

Agora, ao acolher o temporal que se armava, provoca a angustiada interpelação de $\mathrm{Pa}$ linuro.

A tempestade, porém, tem caráter providencial. Graças a ela, Enéias terá oportunidade de homenagear Anquises com cerimônias e jogos, celebrando-lhe o aniversário da morte.

É notório o apreço dado pelos romanos às celebrações de aniversários: comemoravam-se os aniversários das pessoas vivas e mortas, das vitórias importantes e da fundação das cidades. Piganiol (Piganiol, 1923, p. 146), referindo-se a essas comemorações em seu ensaio intitulado "Le sens religieux des jeux", afirma que a realização de jogos fúnebres nos aniversários dos mortos é, para os romanos, um ofício de piedade, um ato que garante a "sobrevivência" do morto, principalmente daqueles que foram "heroicizados" e cuja sobrevivência era necessária para a prosperidade do mundo. Para tal afirmação, baseia-se em dois documentos epigráficos: C.I.L. XIV, 350 (Óstia), no qual se mencionam jogos anuais memoriae Aemiliae Agrippinae; e VIII, 9.052 (Áuzia), no qual se recomenda que se cuide da estátua nos aniversários do morto e se promovam ludi circenses em sua honra.

A homenagem a Anquises é anunciada por Enéias ao raiar da manhã do dia seguinte ao da chegada à Sicília. Serão celebradas pompas solenes, segundo o rito, e depostas as oferendas nos altares. Acestes, troiano que vivia na Sicília e acolhera os conterrâneos na véspera, oferecerá dois bois para cada navio. Além disso, passados nove dias, serão realizados jogos fúnebres, 
("se a nona aurora fizer surgir para os homens um dia ensolarado e cobrir com os raios o mundo").

A referência aos nove dias remete à tradição itálica dos ludi nouendiales que, segundo Sérvio, ocorriam no nono dia que se seguia à cremação. Há numerosas referências aos nove dias de luto, na literatura latina. Horácio, no Epodo 17, fala dos nouendiales pulueres (Ep. 17, 48), numa evidente alusão ao velho costume; Tácito, nos Anais (An. VI, 5), se refere explicitamente às solenidades novendiais que culminavam com um sacrifício e uma refeição. Por outro lado, as Parentalia, festas fúnebres em memória dos mortos da família, mencionadas por Cícero nas Filípicas (Phil. 1, 13) e por Ovídio nos Fastos (F. 2, 548), duravam nove dias (de 13 a 21 de fevereiro).

Virgílio, no relato das homenagens a Anquises, funde as duas tradições: a da comemoração do aniversário da morte e a dos ludi nouendiales.

A cerimônia religiosa descrita no livro V é bastante peculiar. Enéias e os troianos, inclusive os jovens, cobrem as cabeças com murta e se dirigem em procissão ao túmulo de Anquises. Enéias faz libações a Baco, vertendo no solo duas taças de vinho, duas de leite, duas de sangue e flores vermelhas. 0 espírito do morto é invocado (Cf. Il. XXIII, 219) e surge, das profundezas da sepultura, uma imensa serpente azul, com reflexos de ouro. Liba as oferendas e retorna ao interior do túmulo. Enéias, sem saber se se trata de um gênio local ou de um servidor do pai que viera das entranhas da terra, imola duas ovelhas, dois porcos e dois bezerros negros.

A primeira oferenda é comum e apresenta características primitivas. Realiza-se quando o vivo pretende entrar em contato com o morto, contando para isso com a colaboração de deuses ctônicos. Ulisses, na Odisséia (XI, 19 e ss.), também oferece libações aos mortos sob a forma de leite, vinho, água, farinha e finalmente, sangue de vítimas.

A segunda oferenda, entretanto, o sacrifício das ovelhas, porcos e bezerros, é uma autêntica suouetaurilia ${ }^{1}$ - cerimônia de lustração, contada entre as mais antigas práticas religiosas de purificação encontradas na Itália.

Mais uma vez, como de costume, Virgilio mescla tradições heterogêneas na composição de seu poema.

Depois de relatar essas solenidades rituais, o poeta prepara o terreno para falar, enfim, dos jogos:

\section{Exspectata dies aderat nonamque serena}

Auroram Phaetontis equi iam luce uebebant... (V, 104-105)

("Chegara o dia esperado e os cavalos de Fetonte conduziam já a nona aurora com uma luz serena").

\footnotetext{
1 A suouetaurilia, mencionada por Tito Lívio $(I, 44)$, ou seja, o sacrifício ritual de um porco, uma ovelha e um touro, era, entre os romanos, uma das mais antigas práticas de lustração. Presente nas festas agrárias denominadas Ambarualia, descritas por Catão (Cat. Agr. 141), tinha caráter apotropaico.
} 
Descreve então os povos vizinhos, que se juntam na praia para apreciar o certame ou competir, fala dos prêmios que serão oferecidos por Enéias - trípodes, coroas, palmas, armas, vestes de púrpura, talentos de prata e ouro - e menciona a trombeta que anuncia o início das competições.

Narra, então, minuciosamente, os fatos ocorridos durante os jogos: são quase quinhentos versos de narração.

Embora inserido na primeira metade do poema que, como antes dissemos, se baseia na Odisséia, o trecho em que são descritos os jogos se inspira no livro XXIII da Ilíada.

Há diferenças, é certo, entre os dois textos. Virgîlio procura modificar o modelo, mas dele não se distancia muito, conquanto haja, a todo momento, evidente intenção de originalidade. 0 momento da celebração dos jogos é diferente nos dois poemas. No texto homérico, Aquiles convida os gregos a realizarem competições fúnebres em honra de Pátroclo imediatamente após o funeral. Essa prática parece ligar-se à própria origem dos jogos fúnebres helênicos, decorrentes possivelmente de velha crença segundo a qual os mortos deveriam ser homenageados com sacrifícios humanos que teriam sido substituídos pelo sangue dos atletas, derramado durante as competições. No poema virgiliano, como se viu, os jogos se realizam no nono dia após o primeiro aniversário do funeral de Anquises.

As competições descritas na Ilíada e na Eneida também não são exatamente iguais. Aquiles propõe, para homenagear Pátroclo, uma corrida de carros, um pugilato, uma luta livre, uma corrida de velocidade, uma luta de espada, um lançamento de peso à distância, uma competição de tiro de seta e um lançamento de dardo, prova que não chegou a realizar-se. Enéias sugere como homenagem a Anquises uma regata de barcos, uma corrida a pé, lançamento de dardos e de flechas e combate com "cestos". Como na Ilíada, a prova do lançamento do dardo também não é levada a termo mas, em compensação, realiza-se um espetáculo não anunciado anteriormente: um combate simulado de cavalaria que, na época de Augusto, era denominado "jogo troiano".

A descrição da regata é longa, desenrolando-se por mais de cento e oitenta versos. Não se sabe exatamente qual teria sido a razão a fazer com que Virgílio escolhesse uma corrida de barcos em homenagem a Anquises em lugar de uma corrida de carros, mas pode-se propor duas hipóteses, de certa forma imbricadas. As festas náuticas sempre foram populares entre os romanos e durante as Neptunalia, que ocorriam no dia 23 de julho, em homenagem a Netuno, eram realizadas regatas sob a forma de concursos. Como no livro $V$ da Eneida Netuno ocupa lugar importante e sua presença perpassa todo o texto, ${ }^{2}$ não é de estranhar-se a opção pela regata.

\footnotetext{
2 Além de ser interpelado por Palinuro (14) e invocado por Mnesteu (195), Netuno é lembrado por ocasião da referência ao escudo concedido como prêmio de consolação a Niso (360), é chamado por Vênus para proteger os troianos em sua última viagem marítima (779 e ss.), e é quem se compromete a acalmar as ondas e profetiza a morte de Palinuro (799 ss.).
} 
Uma segunda hipótese se vincula ao fato de, entre os gregos, as regatas só terem sido realizadas nos Jogos Ístmicos, os primeiros jogos helênicos de que os romanos participaram como concorrentes. ${ }^{3}$ Eram realizados em honra de Melicertes, filho de Ino, que, segundo a crença, teria sido transformado após a morte no deus marinho Palémon. Palémon é identificado em Roma com Portuno ${ }^{4}$ - mencionado expressamente no canto V - e com Conso, ${ }^{5}$ divindades muito antigas em cuja honra se celebravam festas populares denominadas respectivamente Portunalia e Consualia.

A inserção das regatas, portanto, poderia ser considerada ou como uma espécie de homenagem a Netuno, protetor de Enéias, ou como uma lembrança dos jogos Ístmicos, que admitiam a participação de romanos. Parece-nos que as duas hipóteses são razoáveis.

Virgílio inicia a narração da corrida de barcos, falando dos competidores. Eram quatro embarcações equivalentes (pares/.../carinae - 114-115), conduzidas por remadores e dirigidas pelo comandante competidor. Os nomes dos quatro comandantes-Mnestheus, Gyas, Sergestus e Cloanthus - se aproximam foneticamente dos de quatro importantes familias romanas da época de Virgílio - as gentes Memmia, Gegania, Sergia e Cluentia, propositadamente evocadas pelo poeta.

Os barcos também apresentam pontos em comum com as embarcações romanas do período augustano por ostentarem figuras de monstros na proa (Cf. Prop. IV, vi. 49), dos quais resultam seus próprios nomes.

Apesar dessas preocupações de caráter evidentemente romano e nacionalista, a corrida dos barcos se inspira na corrida de carros descrita na llíada (XXIII, 262-652): é disputadíssima e, por conseguinte, emocionante. Os espectadores vibram, como nas competições atuais:

\section{Tum plausu fremituque uirum studiisque fauentum consonat omne nemus uocemque inclusa uolutant litora; pulsati colles clamore resultant. (V, 148-150)}

("O bosque ressoa então com os aplausos e o frêmito dos homens e com os gritos dos torcedores; a praia fechada faz ecoar as vozes; atingidas pelo clamor, as colinas atroam").

A semelhança entre a corrida de barcos descrita na Eneida e a de carros descrita na Ilíada é facilmente percebida. Em ambos os textos há o mesmo movimento acelerado e pro-

3 De acordo com G. Glotz (Glotz, 1948, p. 517), os Jogos Ístmicos realizados em honra do herói Meliquertes são muito antigos. Sua origem é atribuída a Posêidon ou Teseu. Eram celebrados na primavera, em Corinto, inicialmente de quatro em quatro anos e depois de dois em dois. Constavam de concursos musicais e atléticos, corridas de cavalos e regatas.

4 Portuno é uma antiga divindade etrusca. Considerado originariamente um "deus das passagens", foi cultuado, na época histórica, como um deus marinho, encarregado de vigiar os portos - daí a identificação com Palémon (Cf. Hyg. Fab. 2).

5 Conso, identificado por vezes com Netuno, era na verdade uma divindade ctônica, ligada aos cereais e venerada num pequeno altar subterrâneo, existente no Circo Máximo, e semelhante a un ádyton subterrâneo existente em Corinto, considerado o esconderijo de Palémon (Varr. $L L, \mathrm{VI}, 20$ ). 
gressivo, o mesmo entusiasmo narrativo. Nas duas corridas há percalços e acidentes. A batida de Sergesto contra 0 escolho e sua conseqüente desclassificação equivale ao problema ocorrido com o carro de Eumelo, no texto homérico, à queda do cavaleiro e à sua chegada em último lugar. Na Eneida, o deus Portuno - explicitamente nomeado - ouve as preces de Cloanto e the impele a nau "com sua poderosa mão" (manu magna - 241); na Ilíada, Atena devolve a Diomedes o chicote arrebatado por Apolo, incute vigor a seus cavalos e é diretamente responsável pela quebra do jugo dos animais de Eumelo (Il. XXIII, 391-393). Não importa que para dar "cor local", em seus propósitos nacionalistas, Virgílio se tenhà referido à antiga divindade itálica: a interferência de Portuno é equivalente à de Atena e nela se inspira.

Na prova seguinte, descrita pelo poeta romano - a corrida a pé -, também encontramos traços de semelhança com a de velocidade, presente no poema homérico. Na Ilíada há menos concorrentes; o texto menciona apenas três corredores: Ájax, Ulisses e Antíloco; na Eneida são nomeados sete competidores "além de muitos outros que a fama obscura esconde" (multi praeterea quos fama obscura recondit - Aen. V, 302). Na corrida em homenagem a Pátroclo o ganhador foi Ulisses pois que Atena derrubou Ájax que vinha à frente, quando este escorregou no excremento dos touros do sacrifício (Il. XXIII, 773); na que se realizou em homenagem a Anquises, o vencedor foi o jovem e belo Euríalo. Niso, outro corredor, que logo de saída assumira o primeiro lugar, também escorregou, como Ájax, no sangue das vítimas, perdendo o equilíbrio e a colocação. A novidade virgiliana é a trapaça que se segue. Vendo-se no solo, Niso procurou proteger Euríalo, por quem nutria grande amizade: interpôs-se diante de Sálio, o corredor que assumira a frente, e este também escorregou e caiu. Com isso Euríalo, que antes estava na terceira colocação, conseguiu o primeiro posto e venceu a corrida.

Virgílio procede, pois, a algumas inovações: em lugar de referir-se, nesse passo, a um auxilio divino (cf. $I l$. XXIII, 540-62), mostra um recurso puramente humano, o da vitória dolosa, e cria uma oportunidade para que o corredor que se viu prejudicado se valha de um direito muito atual, usado com grande frequiência - a reclamação fundamentada; além disso, ao descrever a queda de Niso no lodo ensangïentado, constrói um quadro humorístico - como já fizera, aliás, no relato da corrida de barcos, ao mencionar o piloto atirado por Gias ao mar - fazendo com que os espectadores dos jogos riam e se divirtam. Esses pretextos de riso, estranhos, de certa forma, à natureza da épica, são vistos por Saint Denis como uma peculiaridade do espírito latino. ${ }^{6}$

Após essa amena descrição da corrida a pé, Virgílio continua a narrativa e discorre sobre a competição seguinte: o combate do "cesto", espécie de luta de boxe. Trata-se de uma das mais antigas formas de competições, presente na própria origem dos jogos olímpicos (cf.

\footnotetext{
${ }^{6}$ Saint Denis (Saint-Denis, 1965, p. 27 ss.) faz referências explícitas à presença de elementos humorísticos em momentos solenes da vida romana, tais como as cerimônias de núpcias e os funerais.
} 
Glotz, 1948, p. 516) e mencionada por Píndaro na Olímpica X (64-73). Consistia numa espécie de luta em que não apenas a força muscular dos competidores era levada em consideração: valiam-se eles do artifício externo de uma espécie de luva feita de tiras de couro trançado e guarnecida com plaquetas ou bolas de chumbo. Tal objeto era chamado pelos romanos de caestus (cesto): um murro desferido por mão possante enluvada com "cesto" poderia facilmente causar a morte.

Na Ilíada, a competição do pugilato é descrita com certa rapidez, não obstante apresente grande realismo. Os dois competidores se apresentam e o mais forte, Epeio, esmurra 0 rival a ponto de massacrá-lo literalmente. $\mathrm{Na}$ Eneida, a descrição é mais longa. Enéias inicialmente propõe o jogo e apresenta os prêmios. Um guerreiro até então não mencionado, Dares, ${ }^{7}$ se prontifica a competir. Diante do aspecto físico do guerreiro e da força que ostenta, ninguém se atreve a aceitar o desafio. Acestes, porém, o chefe troiano radicado na Sicilia, exorta o velho Entelo a combater, evocando a fama de que desfrutara e o mestre que tivera: Érice, ${ }^{8}$ filho de Vênus, meio-irmão de Enéias. Entelo aceita, apesar da idade avançada, e traz para 0 meio do circo montado os cestos que haviam pertencido a Érice. A luta é dramática e, ao contrário do esperado, Entelo vence o robusto Dares e o teria feito perecer à força de murros se Enéias não interrompesse a contenda.

A descrição do estado do vencido tem o mesmo realismo que se observa no texto homérico e é vazada quase nas mesmas palavras:

\section{Ast illum fidi aequales, genua aegra trabentem iactamque utroque caput crassumque cruorem ore eiectantem mixtosque in sanguine dentes ducunt ad naues... $(\mathrm{V}, 468-471)$}

("Os companheiros fiéis, entretanto, levam para o barco o homem que traz os joelhos feridos, que balança a cabeça de um lado para outro e que lança da boca um sangue espesso e dentes misturados ao sangue...")

0 final da descrição confirma o realismo e toca as raias do exagero. 0 velho Entelo recebe o touro que lhe coubera por prêmio e com a mão direita ainda armada com o cesto desfere violento golpe na cabeça do animal, esmagando-lhe o crânio. Oferece, então, o touro a Érice e depõe junto ao altar, na condição de vencedor, "os cestos e a arte" (bic uictor caestus artemque repono - 484).

A prova seguinte proposta por Enéias é a de tiro de seta. Mais uma vez Virgllio se ins-

\footnotetext{
${ }^{7}$ De acordo com a lliada, Dares era um velho sacerdote de Hefesto, cujo filho morreu na guerra $(I l . \mathrm{V}, 9)$. Dando esse nome a um guerreiro jovem e robusto, Virgílio cria uma personagem estranha à tradição homérica.

8 Segundo a lenda, Érice fora rei da Sicília. Exímio lutador, desafiou Hércules quando este aportou à ilha, de posse dos bois de Gerião, e foi morto pelo herói. Na montanha que tem seu nome (monte Érice), existia um santuário dedicado a Vênus (Cf. Hyg. Fab. 260).
} 
pira no texto homérico. Nos jogos em honra de Pátroclo, a disputa se faz entre dois competidores. Uma pomba fora amarrada por um fio no mastro de um barco. 0 primeiro atirador lança a seta e só consegue romper o fio. 0 segundo atinge a ave em pleno vôo e recebe o prêmio principal.

Virgílio duplica o número dos atiradores. 0 primeiro a lançar a seta atinge o mastro em que também fora atada uma pomba; o segundo rompe o fio, como o de Homero; 0 terceiro mata a ave que escapara. 0 último, Acestes, o hospedeiro dos troianos, já sem alvo e sem possibilidade de palma, atira sua seta a esmo, mostrando apenas sua destreza. Prodigiosamente, porém, a seta se inflama no ar e descreve uma trajetória semelhante à das estrelas cadentes é mais um passo enigmático de Virgílio a merecer, até hoje, diferentes interpretações.

Qual o significado real da seta inflamada?? Prenúncio do próximo incêndio dos navios troianos, queimados por mulheres já cansadas de viajar? Aviso remoto das guerras púnicas? Lembrança do cometa que surgiu em 44 a.C., e que, se de um lado foi compreendido como a metamorfose de Júlio César, de outro foi considerado como uma época brilhante que se iniciaria com Otávio? Alusão às flechas luminosas de Apolo que, segundo a lenda, dirigira o navio de Otávio na batalha de Áctium? Pretexto para que Virgílio zombasse da capacidade dos adivinhos? Prenúncio da apoteose de Enéias, que, como sugere Pichon (apud Piganiol, 1923, p. 59), teria subido aos astros após a morte? (Cf. Ov. Met. XIV, 581 ss.)

A questão permanece aberta para futuras explicações.

Em todos os jogos promovidos por Enéias, há prêmios para os vencedores e prêmios de consolação. Na regata, por exemplo, Cloanto recebe várias recompensas: coroa de louros, novilhos, talento de prata. Recebe também uma clâmide dourada, com larga barra de púrpura, na qual estão bordadas cenas mitológicas referentes a Ganimedes.

0 segundo colocado, Mnesteu, recebe por prêmio uma couraça que pertencera ao grego Demóleo - um presente que tem valor intrínseco e valor histórico. Prêmios desse tipo são também oferecidos aos vencedores da corrida a pé - aljava que pertenceu a uma amazona, capacete argólico, escudo retirado do templo de Netuno - e aos do certame de tiro de seta taça com relevos, que pertenceu a Anquises.

Terminada a narração das competições, Virgílio inicia a descrição do último jogo, especialmente interessante dado o seu caráter original. Trata-se mais de uma exibição de jovens cavaleiros que desfilam diante de um público deslumbrado que propriamente de uma competição.

A descrição é bastante precisa. Virgilio fala do traje resplandecente dos meninos, das cabeleiras comprimidas por coroas, das lanças que trazem, dos cavalos ricamente ajaezados. Alguns têm aljavas presas ao ombro e colares de ouro no peito.

9 Em "Le miracle de la flèche" (Piganiol, 1923, p. 58-61), Piganiol faz importantes reflexões sobre a questão da flecha incandescente, comentando a posição de Plessis e Léjay e discutindo a questão do presságio. 
Participam da exibição três pelotões, cada um constituído de doze meninos, comandados por um capitão. Inicialmente todos se apresentam desfilando. Depois, a um estalo do chicote, os cavaleiros se dividem em duas alas, correm em diversas direções, emparelhados dois a dois, simulam combates, atiram as lanças e se voltam a um outro sinal.

Acrescenta o poeta que tal jogo se chama tróia, que os pelotões são denominados esquadrões troianos e que sua invenção é atribuída a Iulo. Após a fundação de Alba Longa - assim o diz Virgílio - Iulo o teria ensinado aos latinos e estes o teriam preservado até a época de Augusto.

A descrição do jogo - que se assemelha às justas medievais - dá margem a várias observações.

Em primeiro lugar, pode-se verificar que tróia tem mais o caráter de demonstração de habilidade, que propriamente de competição. É uma espécie de "festa de encerramento" e não uma prova a ser disputada, como as anteriores. Tanto que não há prêmios para os pelotões nem proclamação do vencedor. É uma "parada" esportiva, como a considera J. Perret. (Virgile, 1978, p. 158)

Não sendo um jogo de origem grega, e por chamar-se tróia, Virgilio lhe atribui origem troiana. Festus, entretanto, mostra que a palavra troia, com a qual se designava o jogo, se prende aos verbos amptruare e redemptruare (dar voltas, fazer evoluções), e significa volta, evolução. Nada tem de comum, portanto, com o topônimo Tróia. (Virgile, s/d, p. 471-472, n. 7)

Os ludi troiani, segundo Plutarco (Catão de Útica, 3), foram divulgados em Roma na época de Sula; conforme informação de Suetônio, Júlio César, (Diu. Iul. XXXIX), entre os numerosos e variados espetáculos oferecidos à população, promoveu jogos troianos dos quais participaram dois grupos de meninos; Augusto, por sua vez (Aug. XLIII), "freqüentemente mandava celebrar jogos troianos por um escol de meninos, grandes e pequenos, pois julgava belo e digno dos antigos costumes o tornar conhecidos por essa forma os dons de uma estirpe ilustre".

Não é de estranhar-se, portanto, que Virgilio tenha incluído o "desfile troiano", entre os jogos inspirados na epopéia grega.

A inclusão dos ludi troiani talvez até mesmo explique o porquê da reserva de tão grande espaço no livro V para a descrição de competições. Embora Perret procure ver em tal livro uma espécie de preparação para o livro VI, nele se iniciando a construção da figura de Anquises, que vai adensar-se no seguinte, não se pode esquecer de que Virgilio usou freqüentemente a lenda para explicar a história, o passado mítico para justificar o momento em que vivia.

A preocupação de Enéias, promovendo os jogos, se assemelharia à de Júlio César, e sobretudo à de Augusto, que, ao proporcionar ao romano espetáculos de lazer, revestidos ainda de seu caráter religioso, revigorou antigas tradições. A variedade dos espetáculos oferecidos 
ao povo por tais governantes é enfatizada por Suetônio. Segundo o historiador, Júlio César promoveu representações em todos os bairros da cidade, jogos de circo, lutas de atletas, lutas de gladiadores, combate naval simulado, apresentação de danças pírricas e atelanas, corridas de bigas e quadrigas, exercícios de equitação (Diu. Iul. XXXIX); Augusto "ultrapassou todo mundo no tocante à variedade e à magnificência dos espetáculos" (Aug. XLIII), oferecendo ao povo caçadas, batalhas navais, corridas, matanças de feras, desfiles de prisioneiros e mostra de animais insólitos tais como rinocerontes, tigres e enormes serpentes.

Os jogos, na verdade, estão presentes na história romana, desde seus primórdios. Tito Lívio, numa das primeiras páginas de $A b$ Vrbe condita (I, ix, 6-14), ao relatar o rapto das sabinas, se refere aos jogos então promovidos por Rômulo em honra de Netuno, durante cuja realização foram as jovens sequiestradas. A partir desse momento, multiplicam-se as referências a jogos. Não havia, em Roma, é certo, competições regulares à feição dos jogos pan-helênicos, mas a vida romana é ponteada de ludi que se apresentam quer sob a forma de espetáculos (danças, cantos, teatro, apresentação de funambulistas, prestidigitadores e equilibristas), quer de competições agônicas que iam desde as corridas de sacos das Robigalia (Cf. Varr. L.L. 6, 161 e Ovid. $F .4,907)$ até as corridas de mula das Consualia, os campeonatos de pesca do $L u$ di Piscatorii, as corridas de cavalos, as lutas corporais, os munera, ou combates de gladiadores. $\mathrm{Na}$ época imperial havia uma infinidade de oportunidades para a realização de jogos. Além das festas tradicionais, marcadas por espetáculos variados, tais como as Lupercalia, as Parilia, as Cerealia, as Vinalia, as Vestalia, as Volcanalia, celebravam-se em Roma, desde épocas imemoriais, os Ludi Romani, os Ludi Plebeii, os Apolinares, os Megalenses, os Ceriales, os Florales, os Martiales, aos quais se acrescentaram, já no fim da república, os Ludi Victoriae Sullanae e os Ludi Victoriae Caesaris (Carcopino, 1990, p. 242 e seqs.)

Virgilio, com seu texto sobre os jogos fúnebres em homenagem a Anquises, faz eco às vozes de sua época e participa, como em toda a Eneida, da política de reconstrução levada a termo por Augusto.

CARDOSO, Z. A. Virgilius and Trojan - Virgilius and Trojan - Roman funeray games. Classica, São Paulo, v. 9/10, n. 9/10, p. 107-118, 1996/1997.

\section{ABSTRACT}

Tn Aeneid, book $\mathrm{V}$, we find a detailed description of the funerary games organized by Ieneas in order to celebrate the first anniversary of Anchises' death. Although influenced by Homer's Iliad, the text is quite original and offers the opportunity to be commented for focusing the youth parade called Troianus ludus and well-known procedures such as rendering homage to the dead, commemorating the death anniversary of distinguished people and taking part in purification ceremonies, among which the suouetaurilia.

Key-words: Aeneid; Funerary games; Homage to the dead; Sports; Ludus troianus. 


\section{Referências bibliográficas}

AULU-GELLE. Les nuits attiques. Tomes I, II et III. Paris: Garnier, s/d.

CARCOPINO, J. Roma no apogeu do império. São Paulo: Companhia das Letras/Círculo do Livro, 1990.

CATON. De la agricultura. Paris: Les Belles Lettres, 1975.

CICÉRON. Discours. Tome XIX. Philippiques I à IV. Paris: Les Belles Lettres, 1972.

FRIEDLANDER, L. Roman life and manners under the early empire. London: Routledge \& Kegan Paul Ltd., 1965.

GLOTZ, G. Histoire Grecque. Des origines aux guerres médiques. Paris: Presses Universitaires de France, 1948.

GRIMAL, P. Virgile ou la seconde naissance de Rome. Paris: Arthaud, 1985.

GRIMAI, P. Dicionário da Mitologia Grega e Romana. Lisboa: Difel, s/d./ Rio de Janeiro: Bertrand Brasil, s/d.

HYGIN. Fables. Paris: Les Belles Lettres, 1990.

HOMÈRE. Iliade. Paris: Les Belles Lettres, 1949.

HOMÈRE. L'Odyssée. Paris: Garnier, 1947.

HORACE. Oeuvres. Paris: Hachette, s/d.

OVIDE. Les Fastes. Paris: Les Belles Lettres, 1973.

PIGANIOL. Recherches sur les jeux romains. Strasbourg: Istra, 1923.

PINDARE. Oeuvres Complètes. Paris: Garnier, s/d.

PLUTARQUE. Vies. Paris: Les Belles Lettres, 1976.

PROPERCE. Élegies. Paris: Les Belles Lettres, 1970.

SAINT-DENIS, E. Essais sur le rire et le sourire des latins. Paris: Les Belles Lettres, 1965.

SUÉTONE. Les douze Césars. Paris: Garnier, s/d.

TÁCITO. Anales. Madrid: Gredos, 1990.

VARRO. De lingua Latina. Cambridge, Massachussets: Harvard University Press \& London: Heinemann, 1977.

VIRGILE. Oeuvres. Intr. et notes de F. Plessis et P. Léjay. Paris: Hachette, s/d.

VIRGILE. Enéide. Livres V-VIII. Texte et trad. par J. Perret. Paris: Les Belles Lettres, 1978. 